\title{
A prospective assessment of the effect of aminophylline therapy on urine output and inflammation in critically ill children
}

\author{
Robert F. Tamburro ${ }^{1}$, Neal J. Thomas ${ }^{1}$, Gary D. Ceneviva ${ }^{1}$, Michael D. Dettorre ${ }^{1}$, Gretchen L. Brummel ${ }^{2}$ and \\ Steven E. Lucking ${ }^{1}$ \\ Department of Pediatrics, Division of Critical Care Medicine, Penn State Hershey Children's Hospital, Pennsylvania State University College of Medicine, Hershey, \\ PA, USA \\ 2 Pharmacy Administration and Education Department, Milton S. Hershey Medical Center, Pennsylvania State University College of Medicine, Hershey, PA, USA
}

\section{Edited by:}

James Donald Fortenberry, Children's

Healthcare of Atlanta, USA; Emory

University School of Medicine, USA

\section{Reviewed by:}

Rajit Basu, Cincinnati Children's

Hospital Medical Center, USA

Michael Shoykhet, Washington

University in St. Louis School of

Medicine, USA

Christopher W. Mastropietro, Riley

Hospital for Children, USA

*Correspondence:

Robert F. Tamburro, Penn State

Hershey Children's Hospital, Pediatric

Critical Care Medicine, 500 University

Drive, Hershey, PA 17033, USA

e-mail: rtamburro@hmc.psu.edu
Background: Aminophylline, an established bronchodilator, is also purported to be an effective diuretic and anti-inflammatory agent. However, the data to support these contentions are scant. We conducted a prospective, open-label, single arm, single center study to assess the hypothesis that aminophylline increases urine output and decreases inflammation in critically ill children.

Methods: Children less than 18 years of age admitted to the pediatric intensive care unit who were prescribed aminophylline over a 24-h period were eligible for study. The use and dosing of aminophylline was independent of the study and was at the discretion of the clinical team. Data analyzed consisted of demographics, diagnoses, medications, and markers of pulmonary function, renal function, and inflammation. Data were collected at baseline and at 24-h after aminophylline initiation with primary outcomes of change in urine output and inflammatory cytokine concentrations.

Results: Thirty-five patients were studied. Urine output increased significantly with aminophylline use [median increase $0.5 \mathrm{~mL} / \mathrm{kg} / \mathrm{h}$ (IOR: $-0.3,1.3), p=0.05$ ] while blood urea nitrogen and creatinine concentrations remained unchanged. Among patients with elevated C-reactive protein concentrations, levels of both interleukin-6 (IL-6) and IL-10 decreased at $24 \mathrm{~h}$ of aminophylline therapy. There were no significant differences in pulmonary compliance or resistance among patients invasively ventilated at both time points. Side effects of aminophylline were detected in 7 of 35 patients.

Conclusion: Although no definitive conclusions can be drawn from this study, aminophylline may be a useful diuretic and effective anti-inflammatory medication in critically ill children. Given the incidence of side effects, the small sample size and the uncontrolled study design, further study is needed to inform the appropriate use of aminophylline in these children.

Keywords: aminophylline, respiratory function, inflammation, pediatrics, phosphodiesterase inhibition, adenosine receptor blockade, acute kidney injury

\section{INTRODUCTION}

Aminophylline, the ethylenediamine salt of theophylline, is a well-established medication that promotes bronchodilatation by increasing the tissue concentrations of cyclic adenine monophosphate (cAMP) via phosphodiesterase inhibition (1). This pharmacological effect enables it to be useful in the treatment of a number of respiratory conditions including asthma (2). Despite this well documented efficacy, the advent of other bronchodilators that are effective, less prone to toxicity, and easier to administer and monitor has resulted in a dramatic decline in its use for reactive airway disease. However, in addition to its impact on air flow, aminophylline has been demonstrated to have other effects that may be beneficial to the critically ill child. It has been found in a variety of settings to be a useful diuretic and renoprotective agent (3-12). Moreover, various laboratory, animal, and small clinical studies have reported potent anti-inflammatory properties of aminophylline (13-19).

Given these potential renal and anti-inflammatory benefits, and its well-established benefit on bronchoconstriction, aminophylline may benefit a number of critically ill children with a variety of conditions. However, the data to support the use of aminophylline in this patient population is not well established. We undertook a prospective, open-label, and single arm study of the physiologic effects of aminophylline in a tertiary care pediatric 
intensive care unit (PICU). We hypothesized that aminophylline use would augment urine output and decrease inflammation in critically ill children.

\section{MATERIALS AND METHODS}

All patients less than 18 years of age admitted to the PICU who were prescribed aminophylline were screened for inclusion. Patients were excluded if they weighed less than $2.3 \mathrm{~kg}$ or if their initial hemoglobin concentration was less than $8 \mathrm{~g} / \mathrm{dL}$ to minimize the risk associated with the extra blood draw required for the study. The Institutional Review Board of the Pennsylvania State University College of Medicine approved the protocol and informed consent was obtained for all patients enrolled.

The use and dosing of aminophylline was independent of the study and was at the discretion of the clinical team. In our PICU, aminophylline administration is protocolized using an intermittent dosing regimen with a goal theophylline trough of $4-8 \mu \mathrm{g} / \mathrm{mL}$ (Figure 1). Trough concentrations are assessed every $24 \mathrm{~h}$. When administered as a continuous infusion, primarily for severe bronchospasm (e.g., status asthmaticus), target theophylline concentrations are $10-20 \mu \mathrm{g} / \mathrm{mL}$.

Data were collected at baseline prior to the administration of aminophylline, and then again, $24 \mathrm{~h}$ after the initiation of therapy. Collected data consisted of demographics, diagnoses, medications, and vital signs. In addition, data were obtained to assess the impact of aminophylline on renal function, inflammation, and pulmonary function as described below.

\section{RENAL FUNCTION}

Data collected for the assessment of renal function consisted of serum blood urea nitrogen (BUN) and creatinine concentrations,

1) Load: A minophylline $3 \mathrm{mg} / \mathrm{kg}$ load intravenously

2) Maintenance: Begin maintenance dose at next possible standard time $(0400,1000,1600$ or 2200$)$

Age
3 days to 6 weeks
6 weeks to 6 months
6 months to 1 year
1 to 9 years
9 to 12 years
12 to 16 years

Dose
$1.5 \mathrm{mg} / \mathrm{kg} /$ dose every 8 hours
$1.5 \mathrm{mg} / \mathrm{kg} /$ dose every 6 hours
$2 \mathrm{mg} / \mathrm{kg} /$ dose every 6 hours
$3.3 \mathrm{mg} / \mathrm{kg} /$ dose every 6 hours
$2.7 \mathrm{mg} / \mathrm{kg} /$ dose every 6 hours
$2 \mathrm{mg} / \mathrm{kg} /$ dose every 6 hours

3) Therapeutic drug monitoring:

a) Goal trough theophylline concentration: $4-8 \mu / \mathrm{mL}$.

b) This trough concentration is assessed after four maintenance doses have been administered.

c) The trough sample should be drawn immediately before a maintenance dose.

FIGURE 1 |Aminophylline dosing guidelines. The figure depicts the standard intermittent dosing regimen used at the study center. This dosing regimen is based on institution-specific clinical experience. The goal trough theophylline concentration is $4-8 \mu \mathrm{g} / \mathrm{mL}$. This trough concentration is assessed after four maintenance doses have been administered. diuretic use, and urine output. For the baseline determination of urine output, the previous $24 \mathrm{~h}$ prior to aminophylline administration was used. If urine was not collected for an entire $24 \mathrm{~h}$ prior to the aminophylline administration, the urine output for the entire time period prior to aminophylline administration was determined and standardized in terms of milliliters per kilogram per hour. Urine output was also determined by age group to assess if a relationship existed between aminophylline effect and age.

\section{ANTI-INFLAMMATORY EFFECTS}

Data collected for the assessment of inflammation consisted of white blood cell counts, C-reactive protein (CRP) concentrations, glucose concentrations, and anti-inflammatory medication use. Those patients with elevated CRP concentrations, defined a priori as values greater than $1.5 \mathrm{mg} / \mathrm{dL}$ at baseline, underwent measurements of interleukin-6 (IL-6), IL-8, IL-10, and tumor necrosis factor alpha (TNF-alpha). These samples, drawn at baseline (at the same time as the CRP level) and at 24-h, were immediately centrifuged for $10 \mathrm{~min}$. After separation, the plasma was then stored at $-70^{\circ}$ centigrade. Cytokine analysis was performed on only those samples from patients found to have a CRP concentration greater than $1.5 \mathrm{mg} / \mathrm{dL}$ and it was performed utilizing multi-analyte profiling (MAP) technology (Myriad RBM, Inc., Austin, TX, USA). Although 90 different cytokine analyses were performed, it was decided a priori that only the four cytokines listed would be assessed in this study.

\section{PULMONARY FUNCTION}

Data collected relevant to the assessment of pulmonary function included blood gas results, pulse oximeter recordings, and ventilator settings. Additionally, airway resistance and compliance (both static and dynamic) were determined for intubated patients using the assessment tools of the Servo-I ventilator (Maquet Critical Care, Rastatt, Germany) with the patient sedated and not actively breathing over the ventilator.

\section{STATISTICAL ANALYSIS}

Descriptive statistics were performed for all variables; means, standard errors of the mean, medians, and interquartile ranges (IQR). There were two primary outcomes of interest; the effect of aminophylline on urine output and on concentrations of inflammatory cytokines with its impact on pulmonary function being a secondary outcome of interest. Consequently, a Wilcoxon Signed Rank test was performed to compare 24-h after aminophylline therapy values to baseline. To account for potential confounding effects of concomitant medications, total dosages were quantitated and four of the authors (Steven E. Lucking, Gary D. Ceneviva, Neal J. Thomas, Robert F. Tamburro) reviewed all medications and independently determined if there was an increase, a decrease, or no change in the dosing of other diuretics (for renal analysis) and anti-inflammatory medications (for inflammation analysis) across the two time points of the study. The authors were blinded to all outcomes of interest at the time of these determinations. If the authors were not in concordance, the case was discussed until all differences were resolved. A subset analysis was performed on only those patients who received the same or less of these other medications for their respective assessments. An alpha value of 


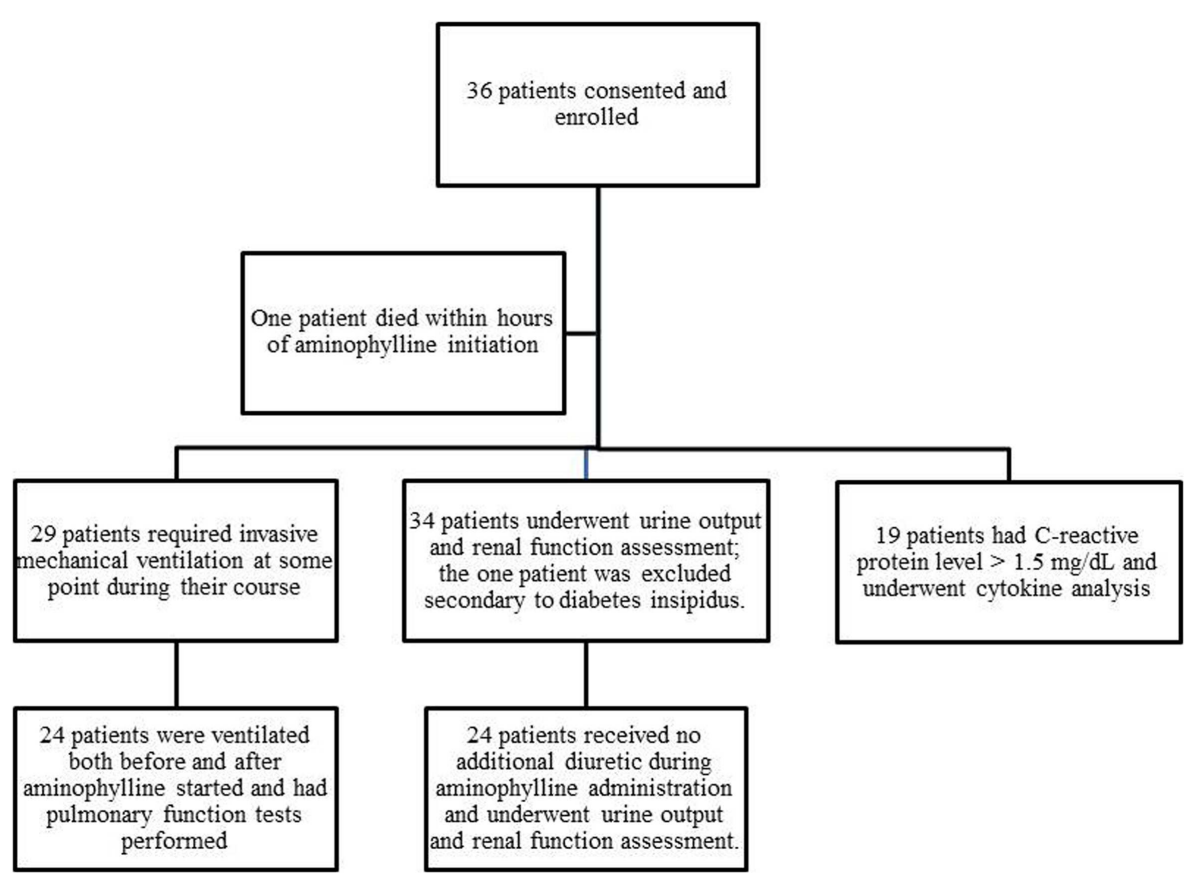

FIGURE 2 | Patients enrolled and assessed in various components of the study. The figure depicts the total enrollment of patients into the trial and the number that underwent the various components of analysis.

0.05 defined statistical significance. Statistical analyses were performed using version 9 of the SAS statistical software program (SAS Institute, Inc., Cary, NC, USA).

\section{RESULTS}

Thirty-six patients were enrolled; 35 were available for analysis because one patient died within hours of enrollment (Figure 2). Ages ranged from 1 week to 18 years. The most common diagnoses included bronchiolitis $(n=9)$, cardiac disease $(n=6)$, and sepsis $(n=6)$ (Table 1).

\section{RENAL FUNCTION}

Thirty-four patients had pre- and post-aminophylline urine output assessed; one patient was excluded from this analysis because of concomitant diabetes insipidus. Among these 34 patients, the urine output increased from a median of 3.5 [IQR: 2.0, 5.0] at baseline to 4.2 [IQR: 2.7, 5.6] at 24-h with a median increase of $1.0 \mathrm{~mL} / \mathrm{kg} / \mathrm{h}$ ([IQR: $-0.1,1.5], p=0.0004)$ (Table 2). The BUN concentrations remained unchanged between baseline and 24-h (median increase $1.0 \mathrm{mg} / \mathrm{dL}$ [IQR: $0.0,4.0$ ], $p=0.16$ ). There was also no change in the creatinine concentrations (median increase $0.02 \mathrm{mg} / \mathrm{dL}$ [IQR: $-0.07,0.07$ ], $p=0.99$ ) (Table 2).

Thirty-one patients received concomitant diuretics during the study period. Ten patients received increased diuretic therapy during the $24 \mathrm{~h}$ of aminophylline therapy. Consequently, urine output was assessed among the 24 patients that received the same or less concomitant diuretics during the $24 \mathrm{~h}$ after the start of aminophylline as during the previous $24 \mathrm{~h}$. Within this subset, the urine output significantly increased with a median increase of $0.5 \mathrm{~mL} / \mathrm{kg} / \mathrm{h}$ per patient ([IQR: $-0.3,1.3], p=0.05$ ) (Table 2).
Fifteen of these 24 patients (63\%) experienced an increased urine output with aminophylline use. There was no change in BUN concentrations among this cohort (median increase 1.0 [IQR: 0.0, 4.0], $p=0.15$ ) nor in creatinine values (median decrease 0.03 [IQR: $-0.08,0.05$ ], $p=0.30$ ) (Table 2).

In an attempt to determine if there was an effect of age on response to aminophylline, urine output was assessed by age group among the 24 patients that received the same or less concomitant diuretics during the $24 \mathrm{~h}$ after the start of aminophylline. Although the numbers are small in each age group, aminophylline appeared to be more effective in the children less than 10 years of age as compared to those over 10 years of age (Figure 3, median change in urine output 1.0 [IQR: $-0.1,1.5$ ] versus -0.2 [IQR: $-0.7,0.1$ ], respectively, $p=0.05$ ).

\section{ANTI-INFLAMMATORY EFFECTS}

There was no change in white blood cell count or glucose concentration between the two time points and comparable results were obtained for these parameters for both the entire cohort and for the subset with elevated CRP concentrations (Table 3). Nineteen patients had CRP concentrations greater than $1.5 \mathrm{mg} / \mathrm{dL}$ and underwent cytokine analysis. For these patients, baseline CRP values ranged from 1.7 to $>27 \mathrm{mg} / \mathrm{dL}$ (median 9.0 [IQR: $4.1,24.3$ ]. The median decrease in IL- 6 concentrations between baseline and $24 \mathrm{~h}$ was $17.6 \mathrm{pg} / \mathrm{mL}$ [IQR: $-5.1,-43.7], p<0.0001$ ) (Table 3). Excluding the three patients who had an increase in their steroid or other anti-inflammatory medications during the $24 \mathrm{~h}$ after the start of aminophylline, yielded comparable results (median decrease 19.0 [IQR: -8.6, -57.7], $p<0.0001$ ) (Table 3). Baseline IL-10 concentrations also differed from 24-h concentrations; the 
Table 1 | Baseline data of entire study cohort

\begin{tabular}{|c|c|}
\hline Variables & \\
\hline \multicolumn{2}{|l|}{ AGE (MONTHS) } \\
\hline Mean & $51.5 \pm 11.5$ \\
\hline Median & 14.8 [IOR: 1.6, 102.5] \\
\hline \multicolumn{2}{|l|}{ GENDER } \\
\hline Males & $23(66 \%)$ \\
\hline Females & $12(34 \%)$ \\
\hline \multicolumn{2}{|l|}{ RACE/ETHNICITY } \\
\hline White & $23(66 \%)$ \\
\hline Hispanic & $10(29 \%)$ \\
\hline African American & $2(6 \%)$ \\
\hline \multicolumn{2}{|l|}{ PRIMARY DIAGNOSIS } \\
\hline Bronchiolitis & $9(26 \%)$ \\
\hline Cardiac disease & $6(17 \%)$ \\
\hline Sepsis & $6(17 \%)$ \\
\hline Pneumonia & $4(11 \%)$ \\
\hline Bronchopulmonary dysplasia & $3(9 \%)$ \\
\hline Near drowning & $2(6 \%)$ \\
\hline Neuromuscular disease & $2(6 \%)$ \\
\hline Tracheal ring & $1(3 \%)$ \\
\hline Thoracic mass & $1(3 \%)$ \\
\hline Status asthmaticus & $1(3 \%)$ \\
\hline \multicolumn{2}{|l|}{ CHEST RADIOGRAPHS } \\
\hline Bilateral disease & $27(77 \%)$ \\
\hline Unilateral disease & $3(9 \%)$ \\
\hline Clear & $5(14 \%)$ \\
\hline \multicolumn{2}{|l|}{ BASELINE RESPIRATORY SUPPORT } \\
\hline Invasive ventilation & $28(80 \%)$ \\
\hline BiLevel Positive Airway Pressure (BiPAP) & $3(9 \%)$ \\
\hline Nasal cannula & $2(6 \%)$ \\
\hline High flow nasal cannula (VapoTherm®) & $1(3 \%)$ \\
\hline Face mask & $1(3 \%)$ \\
\hline
\end{tabular}

median decrease in IL-10 concentrations was 15.0 ([IQR: -3.0, $-33.0], p=0.001$ ) (Table 3). When the three patients who had an increase in their anti-inflammatory medications during the $24 \mathrm{~h}$ after aminophylline initiation were excluded, the median decrease in IL-10 concentrations of 12.0 (IQR: -2.5, -41.0) was comparable to the entire cohort and remained statistically significant $(p=0.009)$ (Table 3). Baseline IL-8 concentrations also differed from 24-h concentrations; (median decrease 14.0 [IQR: -2.0, $-36.0], p=0.05$ ) (Table 3). However, when the three patients who had an increase in their concomitant anti-inflammatory medications were excluded, the median decrease in IL- 8 concentrations of 13.2 (IQR: $-2.2,-41.2$ ) only trended toward significance $(p=0.09)$ (Table 3). TNF-alpha concentrations did not change over the $24 \mathrm{~h}$ study period (Table 3 ).

\section{PULMONARY FUNCTION}

Twenty-eight patients received invasive mechanical ventilation at baseline; three others required non-invasive bilateral positive airway pressure. Twenty-seven (77\%) patients had bilateral lung involvement based on their chest radiograph (Table 1).
Twenty-four patients were invasively ventilated at both time points (prior to aminophylline and at 24-h after the start of aminophylline) and underwent assessment of respiratory function. Among this group, there were no statistically significant differences in static compliance (median change $0.40 \mathrm{~mL} / \mathrm{cm} \mathrm{H}_{2} \mathrm{O}$ [IQR: $-0.45,0.80], p=0.33$ ) or airway resistance (median change $0.5 \mathrm{~cm} \mathrm{H}_{2} \mathrm{O} / \mathrm{L} / \mathrm{s}$ [IQR: $-35.5,4.5$ ], $p=0.29$ ) between the two time points (Table 4). There was an increase in dynamic compliance that approached statistical significance (median change 0.40 [IQR: $0.0,0.60$ ], $p=0.08$ ).

\section{DRUG CONCENTRATIONS AND SIDE EFFECTS}

Aminophylline was administered as a continuous infusion in 3 of the 35 (9\%) patients; the others received it via intermittent dosing. Among the three patients who received aminophylline as a continuous infusion, the 24 -h serum theophylline concentrations were $10.5,12.1$, and $13.9 \mu \mathrm{g} / \mathrm{mL}$. The median 24 -h serum trough theophylline concentration for the patients who received intermittent dosing was 3.7 with a range of $1.1-9.4 \mu \mathrm{g} / \mathrm{mL}$ [IQR: $2.8,5.8$ ].

Side effects were identified in 7 of the 35 patients (20\%) (all receiving intermittent dosing) during their intensive care course, primarily occurring after the defined study period (i.e., after the initial $24 \mathrm{~h}$ of aminophylline therapy) (Table 5). All patients completed at least $24 \mathrm{~h}$ of therapy. Aminophylline was ultimately discontinued in the seven patients; again, none within the first $24 \mathrm{~h}$ of therapy, but three within the first $48 \mathrm{~h}$. Identified side effects included agitation, increased nasogastric output, cardiac ectopy, and tachydysrhythmias (Table 5). Four patients developed dysrhythmias including supraventricular tachycardia, ventricular tachycardia, and pre-mature atrial contractions. Given the critical condition of these children, other explanations existed for the dysrhythmias. Despite the occurrence of these tachydysrhythmias, the baseline median heart rate for the entire cohort was 138 beats per minute [IQR: 127, 151] and remained essentially unchanged at $24 \mathrm{~h}$ (median 141 [IQR: 126, 154], $p=0.74$ ).

\section{DISCUSSION}

In this prospective, open-label, single arm, single center study, the use of aminophylline in critically ill children appeared to be associated with an increase in urine output and a decrease in cytokines of paramount importance to the inflammatory process.

The use of aminophylline for renal protection from acute kidney injury (AKI) is not novel. The efficacy of aminophylline for renal protection has been reported in cisplatin- (3), tacrolimus(4), and contrast-induced $(5,6) \mathrm{AKI}$, in animal models of kidney transplantation (20), and in the vasomotor nephropathy of very pre-term newborns (21). However, its use in critically ill infants and children is not well described. Bell reported a small case series of 10 critically ill children who had a significant increase in urine output with theophylline administration (7). However, in that report, there was no report of BUN or creatinine concentrations, and the concomitant use of low dose dopamine confounded the interpretation and the general applicability of the results. In another small retrospective case series, the administration of aminophylline to five neonates appeared to be associated with an increase in urine output; however, the lack of a bladder catheter complicated interpretation of the study results (8). 
Table 2 | Assessment of renal variables before and after $24 \mathrm{~h}$ of aminophylline.

\begin{tabular}{|c|c|c|c|}
\hline Variable & Baseline value & 24-h value & $p$ Value \\
\hline Urine output ${ }^{a}$ & $3.6 \pm 0.4(3.5[2.0,5.0])$ & $4.7 \pm 0.5(4.2[2.7,5.6])$ & 0.0004 \\
\hline Creatinine ${ }^{b}$ & $0.70 \pm 0.15(0.38[0.27,0.55])$ & $0.75 \pm 0.19(0.34[0.30,0.55])$ & 0.99 \\
\hline \multicolumn{4}{|c|}{ SUBSET THAT RECEIVED THE SAME OR LESS CONCOMITANT DIURETICS DURING THE $24 \mathrm{~h}$ AFTER THE START OF AMINOPHYLLINE ( $n=24$ ) } \\
\hline Urine output ${ }^{a}$ & $3.6 \pm 0.5(3.4[1.9,5.1])$ & $4.4 \pm 0.6(3.5[2.3,5.5])$ & 0.05 \\
\hline Creatinine $^{b}$ & $0.75 \pm 0.18(0.41[0.32,0.69])$ & $0.81 \pm 0.24(0.37[0.31,0.66])$ & 0.30 \\
\hline
\end{tabular}

Both the mean plus/minus the standard error of the mean as well as the median (in parentheses) with the corresponding interquartile range [in brackets] are displayed for each value at each time point.

The $p$ value was determined by the difference of the two values for each patient using the Wilcoxon Signed Rank test and was based on only the patients who had values recorded at both time points.

arine output is reported in terms of milliliters per kilogram per hour.

${ }^{b}$ The units for BUN and creatinine are milligrams per deciliter.

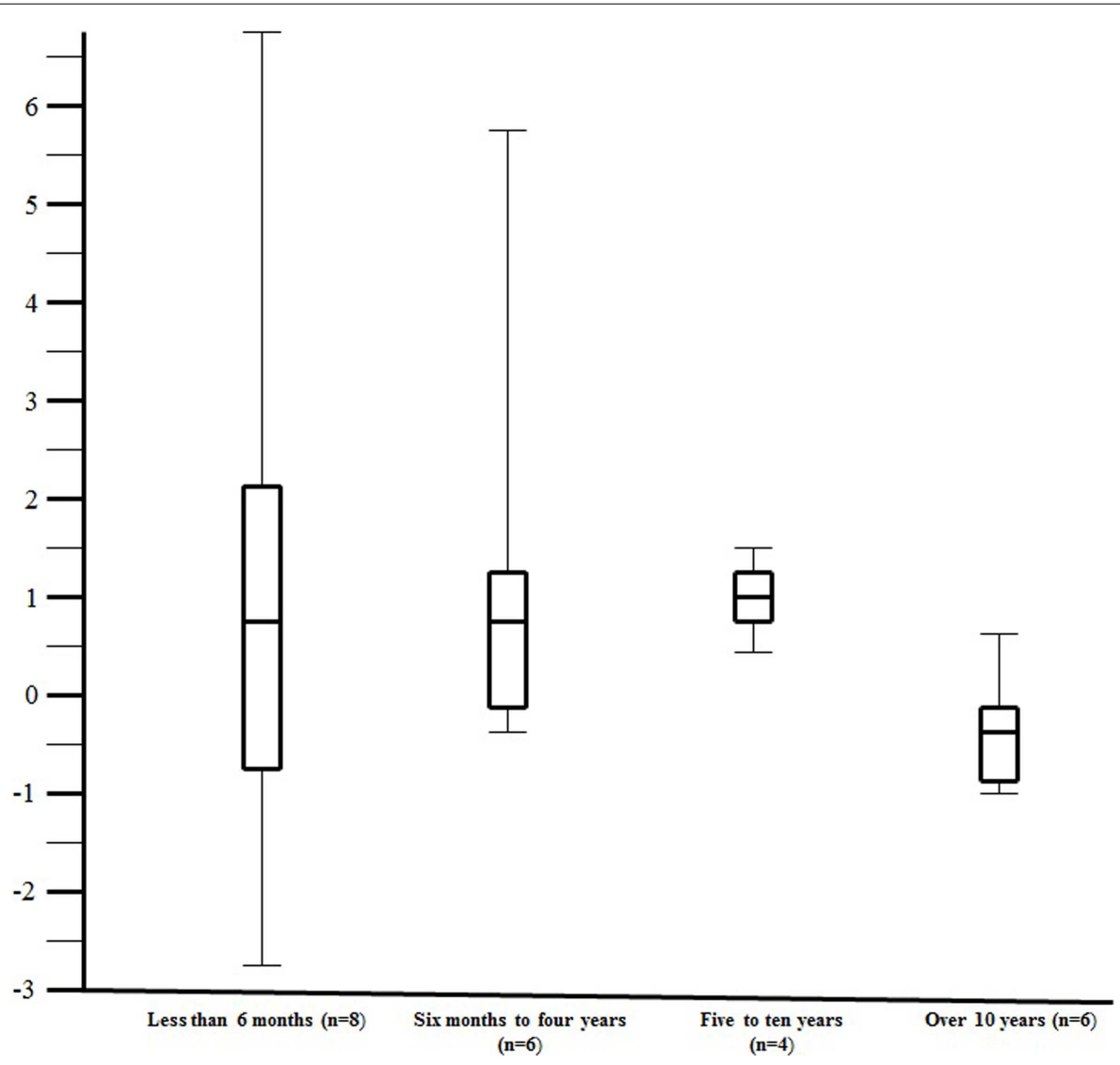

FIGURE 3 |The change in urine output (milliliters per kilogram per hour) over the $\mathbf{2 4} \mathrm{h}$ of aminophylline therapy by age group. The figure illustrates the change in urine output (milliliters per kilogram per hour) over the $24 \mathrm{~h}$ of aminophylline therapy by age group. The change in urine output (milliliters per kilogram per hour) over the $24 \mathrm{~h}$ of aminophylline therapy is plotted along the $y$-axis. The $x$-axis contains the four age groups divided in approximately equal groups. The number of study patients assessed in age group is depicted by the " $n=$ " within the parentheses. The center line within the "box" reflects the median while the ends of the "box" reflect the 25th and 75th percentile, respectively. The "whiskers" extending from the box reflect the entire range of values. 
Table 3 | Assessment of inflammatory parameters before and after $24 \mathrm{~h}$ of aminophylline.

\begin{tabular}{|c|c|c|c|}
\hline Variable & Baseline value & 24-h value & $p$ Value \\
\hline \multicolumn{4}{|c|}{ SUBSET THAT HAD AN ELEVATED C-REACTIVE PROTEIN AT BASELINE $(n=19)$} \\
\hline White blood cella & $11.4 \pm 2.0(9.4[7.5,11.2])$ & $10.9 \pm 1.6(10.0[6.5,12.8])$ & 0.76 \\
\hline IL-6 $6^{c}$ & $156.1 \pm 89.7(27.0[9.4,172.0])$ & $37.3 \pm 13.9(9.4[4.3,20.0])$ & $<0.0001$ \\
\hline IL-8c & $199.7 \pm 69.3(89[51,141])$ & $202.7 \pm 98.1(64[34,99])$ & 0.05 \\
\hline \multicolumn{4}{|c|}{$\begin{array}{l}\text { SUBSET OF ABOVE COHORT THAT RECEIVED THE SAME OR LESS CONCOMITANT ANTI-INFLAMMATORY MEDICATIONS DURING THE } 24 \mathrm{~h} \\
\text { AFTER THE START OF AMINOPHYLLINE }(n=16)\end{array}$} \\
\hline IL-6C & $180.2 \pm 105.9(27.0[12.7,183.0])$ & $42.4 \pm 16.3(7.6[4.3,56.5])$ & $<0.0001$ \\
\hline IL-8 & $218.7 \pm 81.7(85.5[49.5,164.0])$ & $225.4 \pm 116.1(61.0[33.5,157.0])$ & 0.09 \\
\hline IL-10 & $106.1 \pm 53.5(33.0[16.5,48.5])$ & $78.7 \pm 41.0(17.0[13.5,30.0])$ & 0.009 \\
\hline
\end{tabular}

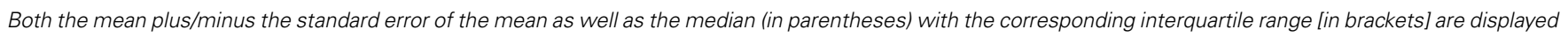
for each value at each time point.

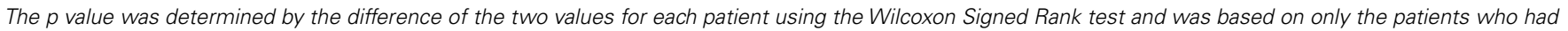
values recorded at both time points.

a White blood cell count expressed in terms of $1000 \mathrm{cells} / \mu \mathrm{L}$.

${ }^{b}$ Blood glucose levels expressed in units of milligrams per deciliter.

${ }^{c}$ Cytokine levels expressed in units of picograms per milliliter.

Table 4 | Assessment of pulmonary variables before and after $24 \mathrm{~h}$ of aminophylline.

Entire cohort intubated and ventilated at both time points $(n=24)$

\begin{tabular}{lccc}
\hline Variable & Baseline value & 24-h value & $\boldsymbol{p}$ Value \\
\hline Static compliance $^{a}$ & $9.5 \pm 2.1(4.4[2.8,14.6])$ & $12.4 \pm 3.0(5.3[3.0,16.4])$ & 0.33 \\
Dynamic compliance $^{a}$ & $8.6 \pm 1.9(3.7[2.3,14.7])$ & $11.3 \pm 3.0(4.0[2.3,18.4])$ & 0.08 \\
Resistance $^{b}$ & $106.1 \pm 13.8(100[34,137])$ & $102.3 \pm 19.5(79[34,142])$ & 0.29 \\
PH & $7.42 \pm 0.01(7.43[7.39,7.47])$ & $248 \pm 0.01(7.46[7.42,7.49])$ & 0.002 \\
SF ratioc & $240 \pm 14(232.5[190,325])$ & 0.17 \\
\hline
\end{tabular}

Both the mean plus/minus the standard error of the mean as well as the median (in parentheses) with the corresponding interquartile range [in brackets] are displayed for each value at each time point.

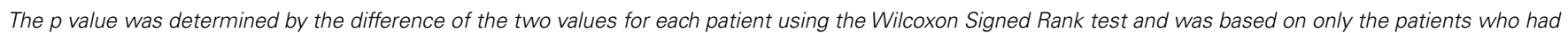
values recorded at both time points.

aThe units for compliance are milliliters per centimeter $\mathrm{H}_{2} \mathrm{O}$.

${ }^{b}$ The units for resistance are centimeter $\mathrm{H}_{2} \mathrm{O} / \mathrm{L} / \mathrm{s}$.

${ }^{c} \mathrm{SF}$ ratio signifies the oxygen saturation to the fraction of inspired oxygen ratio.

Lynch reported a retrospective case series of 13 neonates with non-oliguric AKI and described an improvement in renal function indices with aminophylline (9). However, in that publication, urine outputs were not reported, and many of the subjects were receiving concomitant caffeine, which shares similar properties of aminophylline (9). In a relatively recent retrospective study of nine children with AKI, aminophylline use resulted in improved urine flow rates, stable creatinine concentrations, and a reduced requirement for dialysis (10). Although each of these studies supports a beneficial effect of aminophylline in renal injury, all have significant limitations. The findings of this current report suggest in a prospective manner, with a relatively large sample size, that this therapeutic intervention can increase urine output while not increasing BUN or creatinine concentrations suggesting improved renal perfusion. The results also suggest that this response may be age dependent; however, given the small subgroup sample sizes, this finding can, at best, be used solely to inform future study design.

The purported renal benefits of aminophylline have been attributed to two mechanisms: adenosine receptor blockade at low dosage and type IV phosphodiesterase inhibition at high levels. Adenosine is the putative mediator of tubuloglomerular feedback (22). When the tubule is exposed to increased solute, energy depletion occurs, and adenosine is released. The released adenosine triggers pre-glomerular vasoconstriction thereby limiting solute flow and, in theory, restoring energy balance. In addition 
Table 5 | Characteristics of patients with documented side effects

\begin{tabular}{|c|c|c|c|}
\hline Diagnoses & Side effect & Day & Associated clinical condition \\
\hline \multirow[t]{2}{*}{$\mathrm{S} / \mathrm{P}$ cardiopulmonary arrest } & Increased NG output & 3 & Cardiomyopathy \\
\hline & & & Hypoxic ischemic encephalopathy \\
\hline Pneumonia & PVCs/bradycardia & 2 & Pulmonary hypertension \\
\hline Obstructive sleep apnea & Sinus arrhythmia & & $\begin{array}{l}\text { PVCs resolved with potassium and } \\
\text { magnesium therapy }\end{array}$ \\
\hline Severe septic shock & SVTNT & 3 & Hypotensive, febrile, oliguric, \\
\hline AML & Junctional tachycardia & & acidotic; died 3 days later \\
\hline \multicolumn{4}{|l|}{ ASD repaired 11 years ago } \\
\hline Severe septic shock & SVT & 3 & SVT occurred following albuterol \\
\hline Necrotizing enterocolitis & & & and aminophylline dose; resolved \\
\hline & & & with vagal maneuver \\
\hline Pneumonia & Sinus tachycardia & 2 & Heart rate in the $190-210$ \\
\hline \multicolumn{4}{|l|}{ SMA type 1} \\
\hline RSV bronchiolitis & PACs & 2 & PACs resolved with potassium \\
\hline \multicolumn{4}{|l|}{ TOF (previously repaired) } \\
\hline RSV bronchiolitis & Agitation & 7 & \\
\hline
\end{tabular}

NG, nasogastric; PVCs, premature ventricular contractions; SVT, supraventricular tachycardia; VT, ventricular tachycardia; AML, acute myelocytic leukemia; ASD, atrioventricular septal defect; SMA, spinal muscular atrophy; RSV, respiratory syncytial; PACs, premature atrial contractions; TOF, Tetralogy of Fallot.

to adenosine receptor blockade, aminophylline-induced phosphodiesterase inhibition may prevent the hydrolysis of cAMP, which is important in the mediation of renal blood flow as it promotes renal vasodilatation (23). Both of these mechanisms likely contribute to the improved renal blood flow attributed to aminophylline.

In addition to its effect on the kidneys, significant reductions in cytokines IL-6, IL-10, and to a lesser degree IL-8, were detected following $24 \mathrm{~h}$ of aminophylline therapy. Aminophylline has been found to influence the immune response in other reports. Studies have demonstrated that aminophylline can suppress the release of eosinophil cationic protein (13), induce apoptosis of activated eosinophils (13), inhibit eosinophil chemotaxis in response to multiple stimuli (14), and suppress mitogen-induced secretion of pro-inflammatory cytokines from human peripheral blood lymphocytes (15). In addition, Luo demonstrated significantly lower concentrations of IL-8 and TNF-alpha, and significantly higher concentrations of IL-10 in adult patients receiving aminophylline during cardiopulmonary bypass for valve replacement (24). Although their results differ from ours, they observed a dramatic surge in cytokines after baseline with the use of cardiopulmonary bypass confounding any comparison.

The mechanism by which aminophylline suppresses inflammation is not entirely established. It has been demonstrated that its anti-inflammatory effect can occur at doses significantly smaller than typical bronchodilator doses (i.e., concentrations lower than those needed to produce phosphodiesterase inhibition) (25). Theophylline concentrations on the order of those reported in this study have been found to suppress endotoxininduced TNF-alpha production by monocytes in vivo (26). Thus, it has been postulated that the anti-inflammatory effects may be due to mechanisms other than phosphodiesterase inhibition. Adenosine receptor antagonism (27), an increase in histone deacetylase activity (28), and/or enhanced messenger RNA and protein levels of peroxisomal proliferator-activated receptorgamma (PPAR-gamma) expression (29) have all been reported as potential explanations.

Additionally, aminophylline exerts a number of beneficial effects on pulmonary function via phosphodiesterase inhibition, adenosine receptor antagonism, and increased catecholamine release. In addition to bronchodilation, it has also been found to decrease mucosal edema (30) and excessive secretions (31), enhance respiratory muscle contractility (32) and stimulate the medullary respiratory center (33). In this study, aminophylline was found to have little effect on airway resistance or respiratory compliance. The lack of effect on airway resistance could seemingly be explained by the small and heterogeneous sample. However, other physiologic explanations exist. For example, a large number of patients in the trial had no evidence of increased airway resistance. If bronchospasm is absent, the effects of aminophylline on air flow and respiratory mechanics may be minimal (34). In addition, aminophylline-induced-bronchodilation is proportional to the $\log$ of the plasma theophylline concentration over a range of $5-25 \mu \mathrm{g} / \mathrm{mL}$ (35). It is plausible that the relatively low levels of theophylline attained in this trial were insufficient to induce significant bronchodilation. Moreover, the ability of aminophylline to produce bronchodilation is most likely secondary to phosphodiesterase inhibition and varies from patient to patient (36). In therapeutic doses, aminophylline can only inhibit between 5 and $20 \%$ of total phosphodiesterase activity in human lungs (37). 
Any conclusions drawn from this report regarding aminophylline use must be tempered by the obvious study limitations, and the potential for significant side effects. First, the uncontrolled design of this study confounds any definitive interpretation of the results. It is impossible to determine if the improvement in urine output and the reductions reported in cytokine concentrations were truly the result of aminophylline therapy or the natural course of disease. Although the study patients consisted of a diverse group of diagnoses at variable stages of their disease course, a true effect of aminophylline on urine output and inflammation can only be discerned with the use of an appropriate control group. Second, the study is limited by the small sample size and the diverse patient population. Although the small sample size clearly limits the analysis of the study data and its extrapolation, it is important to note that this study population is larger than any of the previous reports assessing the diuretic and anti-inflammatory properties of aminophylline in critically ill infants and children. Moreover, an analysis by age group was conducted to minimize some of the heterogeneity associated with the large age range of study patients. Finally, the apparent benefits of aminophylline therapy for this patient population must be balanced against the potential for adverse sequelae associated with its use. Although pulmonary, renal and inflammatory effects were assessed for only $24 \mathrm{~h}$, side effects beyond the 24-h study period were reported for completeness.

In light of these clear and acknowledged weaknesses and concerns, the results of this study cannot be considered definitive and the use of aminophylline cannot be routinely recommended for the purposes of augmenting urine output and/or decreasing inflammation in critically ill children. Current national guidelines only suggest that a single dose of theophylline may be administered to neonates with severe perinatal asphyxia at risk for AKI (38). The findings of this study suggest that aminophylline may be of benefit in other populations. A recent publication suggests that it may improve renal function in children with AKI and congenital or acquired cardiac disease admitted to the cardiovascular intensive care unit (39). Given the surge of publications implicating positive fluid balance with worse outcomes in adults (40) and children $(41,42)$, and the established deleterious consequences of uncontrolled inflammation in the critically ill, the use of aminophylline has the potential to be of much benefit for these children. The results of this trial should serve to stimulate and inform well designed, randomized, controlled trials that may provide the needed insight to direct the appropriate use of aminophylline in critically ill children balancing potential benefit against the risk of toxicity.

\section{ACKNOWLEDGMENTS}

This study was conducted with the financial support of the Children's Miracle Network of Penn State Hershey Children's Hospital.

\section{REFERENCES}

1. Lexi-Drugs Online. Aminophylline. (2013). Available from: http://www. crlonline.com/crlonline.Lexi-CompOnline

2. Mitra A, Bassler D, Goodman K, Lasserson TJ, Ducharme FM. Intravenous aminophylline for acute severe asthma in children over two years receiving inhaled bronchodilators. Cochrane Database Syst Rev (2005) 2:CD001276. doi:10.1002/14651858.CD001276.pub2
3. Benoehr P, Krueth P, Bokemeyer C, Grenz A, Osswald H, Hartmann JT. Nephroprotection by theophylline in patients with cisplatin chemotherapy: a randomized, single-blinded, placebo-controlled trial. J Am Soc Nephrol (2005) 16:452-8. doi:10.1681/ASN.2004030225

4. McLaughlin GE, Abitbol CL. Reversal of oliguric tacrolimus nephrotoxicity in children. Nephrol Dial Transplant (2005) 20:1471-5. doi:10.1093/ndt/gfh785

5. Ix JH, McCulloch CE, Chertow GM. Theophylline for the prevention of radiocontrast nephropathy: a meta-analysis. Nephrol Dial Transplant (2004) 19:2747-53. doi:10.1093/ndt/gfh468

6. Dai B, Liu Y, Fu L, Li Y, Zhang J, Mei C. Effect of theophylline on prevention of contrast-induced acute kidney injury: a meta-analysis of randomized controlled trials. Am J Kidney Dis (2012) 60:360-70. doi:10.1053/j.ajkd. 2012.02.332

7. Bell M, Jackson E, Mi Z, McCombs J, Carcillo J. Low-dose theophylline increases urine output in diuretic-dependent critically ill children. Intensive Care Med (1998) 24:1099-105. doi:10.1007/s001340050723

8. Ng GY, Baker EH, Farrer KF. Aminophylline as an adjunct diuretic for neonates - a case series. Pediatr Nephrol (2005) 20:220-2. doi:10.1007/s00467004-1692-9

9. Lynch BA, Gal P, Ransom JL, Carlos RQ, Dimaguila MA, Smith MS, et al. Lowdose aminophylline for the treatment of neonatal non-oliguric renal failure case series and review of the literature. J Pediatr Pharmacol Ther (2008) 13:80-7. doi:10.5863/1551-6776-13.2.80

10. Olowu WA, Adefehinti O. Aminophylline improves urine flow rates but not survival in childhood oliguric/anuric acute kidney injury. Arab J Nephrol Transplant (2012) 5:35-9.

11. Heidemann HT, Bolten M, Inselmann G. Effect of chronic theophylline administration on amphotericin B nephrotoxicity in rats. Nephron (1991) 59:294-8. doi:10.1159/000186567

12. Kuan CJ, Branch RA, Jackson EK. Effect of an adenosine receptor antagonist on acute amphotericin B nephrotoxicity. Eur J Pharmacol (1990) 178:285-91. doi:10.1016/0014-2999(90)90107-H

13. Takeuchi M, Hayakawa A, Takagi K, Hiramatsu K, Shimizu Y, Matsumoto S, et al. Theophylline induces apoptosis of the IL-3 activated eosinophils of patients with bronchial asthma. Apoptosis (1999) 4:461-8. doi:10.1023/A: 1009656527168

14. Numao T, Fukuda T, Akutsu I, Makino S. Effects of anti-asthmatic drugs on human eosinophil chemotaxis. Nihon Kyobu Shikkan Gakkai Zasshi (1991) 29:65-71.

15. Scordamaglia A, Ciprandi G, Ruffoni S, Caria M, Paolieri F, Venuti D, et al. Theophylline and the immune response: in vitro and in vivo effects. Clin Immunol Immunopathol (1988) 48:238-46. doi:10.1016/0090-1229(88)90087-6

16. McKinney GR. On the anti-inflammatory activity of aminophylline. Proc Soc Exp Biol Med (1964) 117:280-3. doi:10.3181/00379727-117-29557

17. Fakioglu H, Gelvez J, Torbati D, Glover ML, Olarte JL, Camacho MT, et al. Aminophylline therapy during endotoxemia in anesthetized spontaneously breathing rats. Pharmacol Res (2004) 49:45-50. doi:10.1016/j.phrs.2003.03.001

18. Lin CC, Lin CY, Liaw SF, Chen A. Pulmonary function changes and immunomodulation of Th 2 cytokine expression induced by aminophylline after sensitization and allergen challenge in brown Norway rats. Ann Allergy Asthma Immunol (2002) 88:215-22. doi:10.1016/S1081-1206(10)61999-0

19. Howell RE, Jenkins LP, Howell DE. Inhibition of lipopolysaccharide-induced pulmonary edema by isozyme-selective phosphodiesterase inhibitors in guinea pigs. J Pharmacol Exp Ther (1995) 275:703-9.

20. Grenz A, Baier D, Petroktistis F, Wehrmann M, Köhle C, Schenk M, et al. Theophylline improves early allograft function in rat kidney transplantation. J Pharmacol Exp Ther (2006) 317:473-9. doi:10.1124/jpet.105.096917

21. Cattarelli D, Spandrio M, Gasparoni A, Bottino R, Offer C, Chirico G. A randomised, double blind, placebo controlled trial of the effect of theophylline in prevention of vasomotor nephropathy in very preterm neonates with respiratory distress syndrome. Arch Dis Child Fetal Neonatal Ed (2006) 91:F80-4. doi:10.1136/adc.2005.073650

22. Li L, Lai EY, Huang Y, Eisner C, Mizel D, Wilcox CS, et al. Renal afferent arteriolar and tubuloglomerular feedback reactivity in mice with conditional deletions of adenosine 1 receptors. Am J Physiol Renal Physiol (2012) 303:F1166-75. doi:10.1152/ajprenal.00222.2012

23. Thomas NJ, Carcillo JA. Theophylline for acute renal vasoconstriction associated with tacrolimus: a new indication for an old therapeutic agent? Pediatr Crit Care Med (2003) 4:392-3. doi:10.1097/01.PCC.0000075322.56699.83 
24. Luo WJ, Ling X, Huang RM. Effects of aminophylline on cytokines and pulmonary function in patients undergoing valve replacement. Eur J Cardiothorac Surg (2004) 25:766-71. doi:10.1016/j.ejcts.2004.02.024

25. Sullivan P, Bekir S, Jaffar Z, Page C, Jeffery P, Costello J. Anti-inflammatory effects of low-dose oral theophylline in atopic asthma. Lancet (1994) 343:1006-8. doi:10.1016/S0140-6736(94)90127-9

26. Spatafora M, Chiappara G, Merendino AM, D’Amico D, Bellia V, Bonsignore G. Theophylline suppresses the release of tumour necrosis factor-alpha by blood monocytes and alveolar macrophages. Eur Respir J (1994) 7:223-8. doi:10.1183/09031936.94.07020223

27. Yasui K, Agematsu K, Shinozaki K, Hokibara S, Nagumo H, Nakazawa T, et al. Theophylline induces neutrophil apoptosis through adenosine A2A receptor antagonism. J Leukoc Biol (2000) 67:529-35.

28. Ito K, Lim S, Caramori G, Cosio B, Chung KF, Adcock IM, et al. A molecular mechanism of action of theophylline: induction of histone deacetylase activity to decrease inflammatory gene expression. Proc Natl Acad Sci U S A (2002) 99:8921-6. doi:10.1073/pnas.132556899

29. Usami A, Ueki S, Ito W, Kobayashi Y, Chiba T, Mahemuti G, et al. Theophylline and dexamethasone induce peroxisome proliferator-activated receptor-gamma expression in human eosinophils. Pharmacology (2006) 77:33-7. doi:10.1159/ 000092376

30. Erjefalt I, Persson CG. Anti-asthma drugs attenuate inflammatory leakage of plasma into airway lumen. Acta Physiol Scand (1986) 128:653-4. doi:10.1111/j. 1748-1716.1986.tb08027.x

31. Cotromanes E, Gerrity TR, Garrard CS, Harshbarger RD, Yeates DB, Kendzierski DL, et al. Aerosol penetration and mucociliary transport in the healthy human lung: effects of low serum theophylline levels. Chest (1985) 88:194-200. doi:10.1378/chest.88.2.194

32. Murciano D, Aubier M, Lecocguic Y, Pariente R. Effects of theophylline on diaphragmatic strength and fatigue in patients with chronic obstructive pulmonary disease. $N$ Engl J Med (1984) 311:349-53. doi:10.1056/ NEJM198408093110601

33. Haidmayer R, Kenner T. Physiological approaches to respiratory control mechanisms in infants. Assessing the risk for SIDS. Ann N Y Acad Sci (1988) 533:376-89. doi:10.1111/j.1749-6632.1988.tb37266.x

34. Seligman M. Bronchodilators. Third ed. In: Chernow B, editor. The Pharmacologic Approach to the Critically Ill Patient. Baltimore, MD: Williams \& Wilkins (1994). p. 567-78.

35. Mitenko PA, Ogilvie RI. Rational intravenous doses of theophylline. N Engl J Med (1973) 289:600-3. doi:10.1056/NEJM197309202891202

36. Bergstrand H. Phosphodiesterase inhibition and theophylline. Eur J Respir Dis Suppl (1980) 109:37-44.

37. Anderson M. The properties of aminophylline. Emerg Nurse (2007) 15:24-7. doi:10.7748/en2007.11.15.7.24.c6254
38. Kidney Disease: Improving Global Outcomes (KDIGO) Acute Kidney Injury Work Group. KDIGO clinical practice guideline for acute kidney injury. Kidney Int Suppl (2012) 2:1-126. doi:10.1038/kisup.2012.2

39. Axelrod DM, Anglemyer AT, Sherman-Levine SF, Zhu A, Grimm PC, Roth SJ, et al. Initial experience using aminophylline to improve renal dysfunction in the pediatric cardiovascular ICU. Pediatr Crit Care Med (2014) 15:21-7. doi:10.1097/01.pcc.0000436473.12082.2f

40. National Heart, Lung, and Blood Institute Acute Respiratory Distress Syndrome (ARDS) Clinical Trials Network, Wiedemann HP, Wheeler AP, Bernard GR, Thompson BT, Hayden D, et al. Comparison of two fluid-management strategies in acute lung injury. N Engl J Med (2006) 354:2564-75. doi:10.1056/ NEJMoa062200

41. Valentine SL, Sapru A, Higgerson RA, Spinella PC, Flori HR, Graham DA, et al. Fluid balance in critically ill children with acute lung injury. Crit Care Med (2012) 40:2883-9. doi:10.1097/CCM.0b013e31825bc54d

42. Willson DF, Thomas NJ, Tamburro R, Truemper E, Truwit J, Conaway M, et al. The relationship of fluid administration to outcome in the pediatric calfactant in acute respiratory distress syndrome trial. Pediatr Crit Care Med (2013) 14:666-72. doi:10.1097/PCC.0b013e3182917cb5

Conflict of Interest Statement: Neal Thomas serves as a consultant for Discovery Laboratories and receives funding for his efforts. Gretchen Brummel works as a consultant for Lexicomp, a "Pharma-free" drug information vendor, and receives pay for her services. She is a former Lexicomp employee. Robert Tamburro and Neal Thomas receive funding including salary support from the United States Food and Drug Administration Office of Orphan Product Development Grant Program. We have no other conflicts to disclose.

Received: 15 March 2014; accepted: 25 May 2014; published online: 12 June 2014. Citation: Tamburro RF, Thomas NJ, Ceneviva GD, Dettorre MD, Brummel GL and Lucking SE (2014) A prospective assessment of the effect of aminophylline therapy on urine output and inflammation in critically ill children. Front. Pediatr. 2:59. doi: 10.3389/fped.2014.00059

This article was submitted to Pediatric Critical Care, a section of the journal Frontiers in Pediatrics.

Copyright (c) 2014 Tamburro, Thomas, Ceneviva, Dettorre, Brummel and Lucking. This is an open-access article distributed under the terms of the Creative Commons Attribution License (CC BY). The use, distribution or reproduction in other forums is permitted, provided the original author(s) or licensor are credited and that the original publication in this journal is cited, in accordance with accepted academic practice. No use, distribution or reproduction is permitted which does not comply with these terms. 